\title{
Correction to: Allegations of Sexual Misconduct: A View from the Observation Deck of Power Distance Belief
}

\author{
Shalini Sarin Jain ${ }^{1}$ Joon Sung Lee ${ }^{2}$
}

Published online: 1 December 2020

๑) Springer Nature B.V. 2020

Correction to: Journal of Business Ethics

https://doi.org/10.1007/s10551-020-04644-9

The initial online publication contained a typesetting mistake. The original article has been corrected.

Publisher's Note Springer Nature remains neutral with regard to jurisdictional claims in published maps and institutional affiliations.

The original article can be found online at https://doi.org/10.1007/ s10551-020-04644-9.

\section{Shalini Sarin Jain}

ssj8@uw.edu

Joon Sung Lee

leejs929@yonsei.ac.kr

1 Milgard School of Business, University of Washington Tacoma, 1900 Commerce Street, P.O. Box 358420, Tacoma, WA 98402, USA

2 Department of Sport Industry Studies, College of Educational Sciences, Yonsei University, 50 Yonsei-ro Seodaemun-gu, Seoul, Korea 